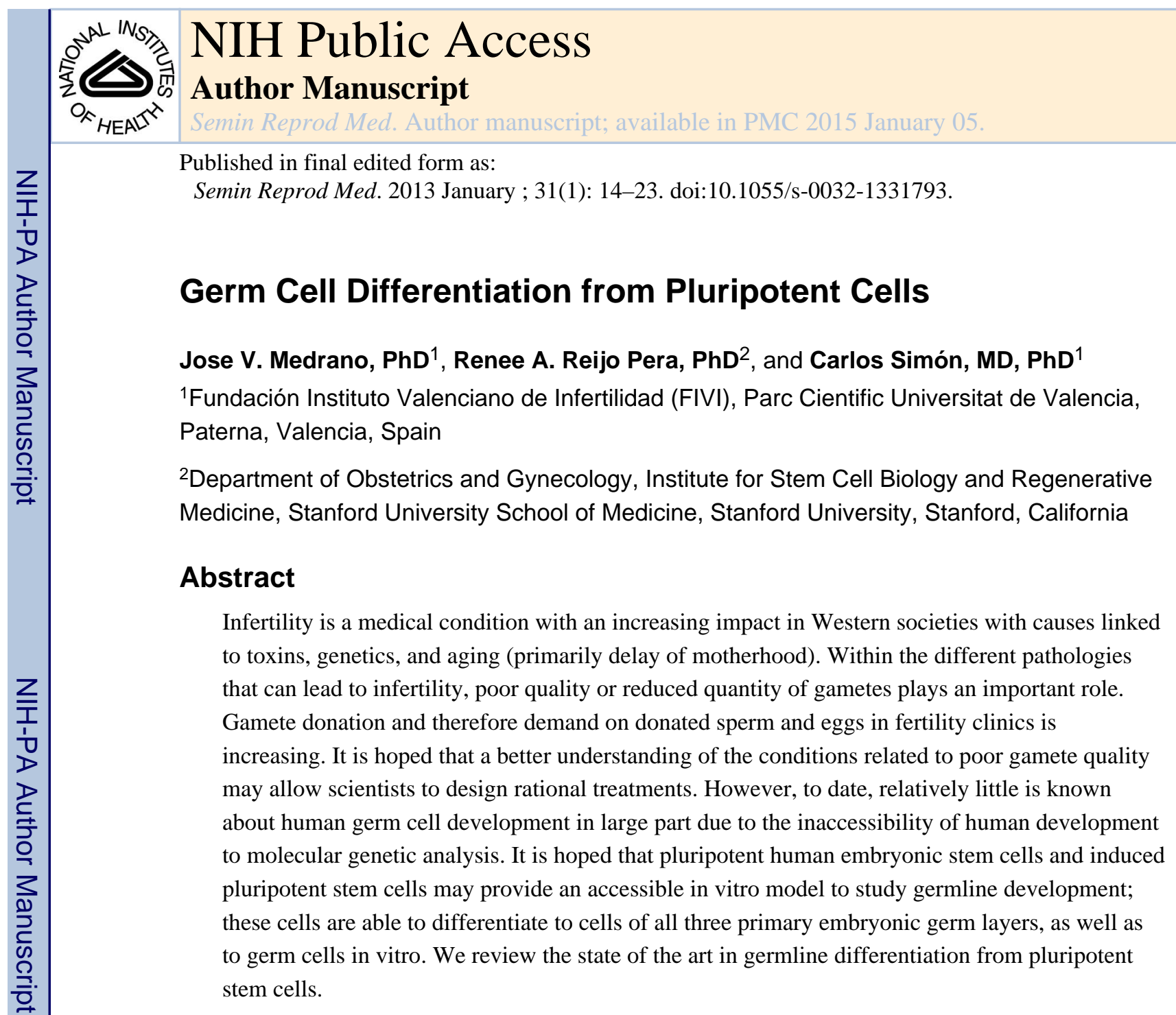

\title{
Keywords
}

differentiation; germ cells; induced pluripotent stem cells; human embryonic stem cells

\begin{abstract}
Germ cells are responsible for the transfer of genetic information to offspring in species with sexual reproduction such as mammals. A key characteristic of germ cells is their ability to reduce their diploid genetic information to form haploid gametes through meiosis. Only haploid functional gametes are able to combine and form a viable human embryo following fertilization. Thus gametes play an essential role in the reproduction of mammals in general, and humans in particular.

According to the World Health Organization (WHO), infertility affects up to $14 \%$ of couples of reproductive age with a trend toward increased incidence linked primarily to toxins and aging (the delay of motherhood in the developed world). ${ }^{1}$ Based on the 2005 National Survey on Family Growth American report, $12 \%$ of American couples experienced
\end{abstract}

Copyright $@ 2013$ by Thieme Medical Publishers, Inc.

Address for correspondence and reprint requests Jose V. Medrano, PhD, Fundación Instituto Valenciano de Infertilidad (FIVI), Parc Científic Universitat de Valencia, Catedrático Agustín Escardino 9, 46980 Paterna (Valencia), Spain (jose.medrano@ivi.es).. 
impaired fertility in 2002, which implies a $20 \%$ increase from the 6.1 million couples who reported an inability to have children in 1995.

Donation of sperm and eggs is usually the solution in the most severe cases when fertility problems are linked to the unavailability of gametes of sufficient quality for reproductive purposes. A report of assisted reproduction cycles performed in the year 2000 in 49 countries worldwide indicated that $\sim 32 \%$ of procedures involved egg donation. ${ }^{2}$ The U.S. Department of Health and Human Services stated that in the United States alone in 2004, $12.5 \%$ of assisted reproduction cycles were performed with donor eggs. Also, in the report of assisted reproductive techniques (ART) from treatments initiated during 2002, published by the European Society of Human Reproduction and Embryology (ESHRE) in 2006 (European in vitro fertilization [IVF] monitoring program [EIM]), the proportion of ART cycles with egg donation increased to $22.4 \%$, with a $34.9 \%$ pregnancy rate per transfer. Despite the variation in results from different reports, there is a clear consensus that poor quality gamete formation is a major and important cause of infertility, a cause that is difficult to circumvent. However, even though donation of gametes results in very high pregnancy rates, there are ethical, legal, and personal concerns to consider. These concerns also fuel an increasing scientific interest in the study of germline development and differentiation.

Most information regarding human germ cell development has been extrapolated from studies of other species, especially mouse germ cell development in vivo. ${ }^{3-6}$ Therefore, our knowledge of development in humans is limited, mainly due to the inaccessibility of early human development to molecular and genetic analysis of germ cells. In this sense, the use of pluripotent stem cells as an in vitro model for the study of germ cell differentiation is a promising source of knowledge. ${ }^{7}$

The discovery of pluripotent stem cells marks an important breakthrough in biological sciences, leading to the creation of a new field termed regenerative medicine. Embryonic stem cells (ESCs) can be derived from the inner cell mass of embryos and have the ability to self-renew and remain undifferentiated under proper culture conditions, but they can also differentiate to all the cell types in the organism. ${ }^{8-10}$ More recently, induced pluripotent stem cells (iPSCs), cells with many similarities to human ESCs (hESCs), have been obtained by reprogramming adult cells with a cocktail of four transcription factors: OCT4, SOX2, KLF4, and c-MYC. The resulting iPSCs resemble and share many characteristics with ESCs, representing an alternative to the use of hESCs that may overcome some difficulties of hESCs and also allow genetic matching of stem cells to the individual. ${ }^{11}$ Both ESCs and iPSCs have been shown to differentiate to cells of all three embryonic germ layers, the endoderm, mesoderm, and ectoderm, as well as to germ cells in vitro. Thus they should provide a model for the study of the genetics and epigenetics of the human germline. In this way, the development and improvement of the research on ESC and iPSC-derived gametes has gained attention in the last few years.

We review the fundamentals of germline development in mammals and update readers on recent clinical and research advances in the study of the human germ cell differentiation from pluripotent stem cells. We focus on major problems that have been encountered and 
future efforts that the scientific community will need to address for a better understanding of germline development.

\section{Germline Development in Mammals}

To understand the scientific efforts that different groups have been conducting in the last several years to achieve germline in vitro differentiation from human pluripotent stem cell lines, we briefly review the basics of germline development in mammals (Fig. 1). Most of the data we present here were obtained from model organisms such as rodents. Thus it is quite possible that some of the major events portrayed here may be different in humans, a major driver for investigating the use of human pluripotent stem cells as tools to investigate human germline development.

\section{Specification, Migration, and Colonization of Gonadal Crests}

In humans and mammals in general, the germline originates from a founder pluripotent cell population called primordial germ cells (PGCs) that segregate from the somatic lineage during the early stages of embryogenesis. In mice, the bone morphogenetic proteins 4 (BMP4) and 8 (BMP8) secreted by adjacent extraembryonic endoderm induce a population of cells in the proximal epiblast to express Blimp1 (also known as PR Domain zinc finger protein 1 [Prmd1]). ${ }^{5,6,12-14}$ Blimp1 acts as a repressor of the somatic program of the cells that respond to the BMP signaling and is considered the activator of the germinal fate of the first population of PGCs that appears in the base of allantois at E7.5 in mice ${ }^{3,15,16}$ (Fig. 1). In a similar way, the first detectable population of PGCs appears out of the embryo, close to the yolk sac around the second and the third week of pregnancy in humans.

Among all the cells in the proximal epiblast that respond to the induction of the extraembryonic endoderm, only the subpopulation of committed PGCs start to express Fragilis (also known as InterFeron Induced TransMembrane protein 1 [Iftm1]) and Stella (also known as Developmental PluriPotency Associated 3 [Dppa3] 5,16 and retain the expression of the pluripotency-associated transcription factors OCT4 (also known as POU class 5 homeobox 1 [Pou5f1]) and NANOG, as well as alkaline phosphatase activity after gastrulation $^{2,17-19}$ (Fig. 1).

Just after their specification, PGCs proliferate and migrate through adjacent endoderm to the genital ridges. ${ }^{4,16-19}$ This migration occurs between E8.5 and E12.5 and the fourth and sixth week of pregnancy in mice and humans, ${ }^{17-19}$ respectively. It appears that the survival and migration of PGCs during this time is regulated by the activation of different pathways regulated by the Phosphatidyl Inositol 3 Kinase (PI3K) in response to the steel factor (also known as KIT ligand), as shown by the high levels of c-KIT that PGCs express during this migration phase. ${ }^{20}$

Once PGCs colonize genital ridges, they are termed gonocytes and are characterized by a rounded morphology, with a low cytoplasm-to-nucleus ratio. ${ }^{21}$ Also at this stage, the germ cells begin a significant change in their genetic and epigenetic expression profiles and start to express (or increase the expression of) some genes considered essential for their survival and maturation such as Deleted in AZoospermia-Like (Dazl) and VASA. ${ }^{22-24}$ 


\section{Sex Specification, Meiosis, and Germ Cell Maturation}

Sexual determination of germ cells is thought to depend more on the sex of the gonadal niche (the somatic cells) than on the sex chromosome composition of the germ cells per se. ${ }^{25}$ In this way, the expression of SRY, encoded in the short arm of the Y chromosome, drives the male sexual differentiation of germ cells indirectly rather than cell autonomously. SRY activates the expression of SOX9 in the supporting cells of the gonadal niche and induces its differentiation to Sertoli cells. In turn, Sertoli cells drive differentiation of the bipotential gonad into the male testis by inducing the degeneration of the Müllerian duct in response to the anti-Müllerian hormone (AMH) ${ }^{26-29}$ (Fig. 2).

Female gonadal determination seems to be quite different from the male counterpart. Available evidence suggests that ovarian development may occur independently of the germline and the somatic lineages (granulosa and theca cells) because germ cells that migrate outside of the ovary acquire oocyte-like morphology even if they are $\mathrm{XX}$ or $\mathrm{XY}$ cells. ${ }^{30-32}$

Once they have determined their sex, male and female germ cells also differ in the time point to enter meiosis. In the female gonad, germ cells generally enter meiosis and stay arrested in the first meiotic prophase during embryonic development around E13.5 in mice or week 12 in humans, ${ }^{33,34}$ whereas in males, spermatogonia arrest in mitosis and do not enter meiosis until puberty. ${ }^{18,33}$

Both the ovary and testis share a signaling system to induce germ cell meiosis, although at different timing, as already explained. Retinoic acid (RA) produced from the mesonephros during development of both sexes or Sertoli cells during male adulthood is a key regulator responsible for the induction of germ cell meiosis in the developing ovary by inducing the expression of the Stra 8 gene. ${ }^{34}$ However, in the fetal testis, SRY induces the degradation of RA by the activity of cytochrome P450 encoded by the Cyp26b1 gene in Sertoli cells. This gene is expressed in the bipotential gonad of both male and female embryos to prevent meiosis in the germ cells when they first arrive at the gonad and come into contact with RA. However, once sex is determined, its expression becomes specific only in male testis until they reach puberty when hormonal changes switch off its expression and activates RA secretion in Sertoli cells, allowing spermatogonia to divide and enter meiosis. ${ }^{35}$

Before meiotic initiation, there is a temporary silencing of pluripotency-related genes such as OCT4. ${ }^{36,37}$ Once this silencing occurs and meiosis is initiated, chromosomal synapsis is promoted by an evolutionarily conserved meiosis-specific protein structure, the synaptonemal complex, which is formed by synaptonemal complex proteins SCP1, SCP2, and SCP3, among others. ${ }^{38-40}$ These SCPs are meiosis-specific proteins essential for the synapses of homologous chromosomes because errors of synapses result in defects in homologous chromosomes pairing and meiotic recombination, and these irregularities can contribute to meiotic arrest. ${ }^{41}$ It has been suggested that SCP3 could be a target for DAZLmediated translation in mammals. Thus azoospermia associated with a decrease in DAZ gene function in humans may in part be a consequence of failure at synapsis caused by reduced levels of SCP3 protein. ${ }^{42}$ 
Finally, gamete maturation is different between sexes. In males, spermatogenesis starts just after puberty and is initiated by asymmetric divisions of spermatogonia and followed by the differentiation into meiotic spermatocytes I. Once meiosis occurs, haploid spermatocytes II start the second step called spermiogenesis. It consists in significant morphological and epigenetic changes including the replacement of histones by protamines to form mature sperm. ${ }^{18,33,43}$ Conversely, female gamete maturation in mammals occurs in waves following hormonal cycles that recruit pools of primordial follicles to progress through asymmetric meiosis. After the gonadotropin dependence is reached, a cohort of follicles is recruited, but only one will reach the metaphase II stage escaping the selection process called atresia.

Metaphase II ovulated oocytes only finish meiosis after sperm activation during fertilization. ${ }^{18,44}$

\section{Epigenetics of Germline Differentiation}

Epigenetics consists, in its simplest form, in modifications of DNA and chromatin that regulate the expression or silencing of genes without altering the primary DNA sequence. Epigenetics can modify both DNA and histones by several mechanisms such as methylation, phosphorylation, acetylation, or ubiquitination. Methylation is related to the incorporation of methyl groups by DNA methyl-transferases (DNMTs) that may impart control of promoters and gene expression in a temporal manner. ${ }^{45}$ DNMT1 acts to maintain epigenetic marks during DNA replication, whereas DNMT3a and DNMT3b act primarily to establish de novo methylation during differentiation. ${ }^{46,47}$

Genetic imprinting occurs when the two alleles of a gene are differentially modified, often via differential methylation, in a parental-specific manner. In this way, genetic imprinting is a fine-tuned regulatory mechanism for the temporary and tissue-specific expression of the paternal/maternal allele during development. ${ }^{48,49}$ This mechanism is sequentially established and erased in the germinal lineage but not in somatic tissues ${ }^{50-52}$ (Fig. 1). During the specification of the germ cell lineage, the PGCs undergo DNA demethylation when they reach the gonadal ridge, and imprinting is erased. This epigenetic erasure is important to activate expression of several silenced genes whose expression is critical for terminal differentiation of germ cells. ${ }^{53}$ Subsequent reacquisition of methylation patterns in a sex-dependent manner follows; during spermatogenesis, this occurs before the onset of meiosis, whereas in oogenesis it occurs just after the onset of meiosis. Imprinting can be modified postfertilization during early embryo development, depending on its chromosomal sex as well. ${ }^{54,55}$

Although the number of imprinted genes represents $\sim 5 \%$ of the whole human genome, these genes have critical effects on temporal and spatial regulation of fetal growth and development. Correct imprinting is mandatory in gametes and the fertilized zygote for proper development and cell function. Imprinting alterations are implicated in abnormal fetal development and several diseases such as Prader-Willi, Angelman, BeckwithWiedemann, and Russell-Silver. ${ }^{56,57}$ Therefore epigenetics and imprinting regulation of the germline must be considered when differentiation of gametes from ESC is attempted because it is possible that generation of gametes in vitro from ESC modifies the epigenetic 
reprogramming and might induce alterations in embryonic growth and development, as we note in the following sections. ${ }^{58}$

\section{Pluripotent Stem Cells as a Source of Germ Cells in Vitro}

Accumulated evidence demonstrates that in vitro generation of germ cells from pluripotent stem cells is relatively robust. However, the following stages of gametogenesis and the creation of functionally mature gametes is very infrequent and likely to yield products that remain uncertain in terms of safety and effectiveness. In this section, we briefly review the most important advances in the field to offer a concise view of the state of the art with the latest advances and main challenges.

\section{State of the Art in Germ Cell Differentiation from Mouse ESCs}

In 2003, the scientific community heard the first reports of germline differentiation from mouse ESCs (mESCs). ${ }^{59} \mathrm{mESC}$ lines expressing green fluorescent protein (GFP) under control of a germ cell-specific reporter were spontaneously differentiated; upon differentiation, GFP-positive cells were selected, and the authors reported apparent folliclelike structures that spontaneously started to detach from the monolayer and extrude oocytelike cells (OLCs). These OLCs were reportedly activated by parthenogenesis and formed pseudo-blastocysts. Interestingly, this phenomenon was observed in both male and female mESC cell lines, suggesting that in the absence of the expression of Sry from the gonadal niche, germ cells differentiate to a female phenotype. ${ }^{25}$ The same year, another group reported differentiation of sperm-like cells from mouse ESCs. ${ }^{60}$ The authors transfected mESCs with the postmigratory germ cell marker mouse VASA homologous (Mvh) promoter associated with GFP and differentiated them in three-dimensional coaggregates with a M15 cell line that secretes BMP4. Mvh-GFP positive cells were transplanted into host testes where they participated in spermatogenesis in vivo. However, this work reported no data about the fertilization capacity of these artificially generated gametes. ${ }^{60}$

Subsequently, functionality of germ cells derived in vitro was reported by Nayernia and colleagues when they differentiated mESCs in embryoid bodies (EBs) and putative germ cells SSEA1 + /OCT4+ were isolated and further cultured in the presence of RA to induce their meiotic entrance. ${ }^{61}$ The resulting haploid cells were reported to have an epigenetic pattern of the imprinted genes Igf $2 r$ and $H 19$ according to mature male gametes, and their functionality was assessed by the formation of blastocysts after their injection in mouse oocytes by intracytoplasmic sperm injection (ICSI). ${ }^{61}$ In addition to these works, several reports have used different approaches with similar results. ${ }^{62-64}$ Together, however, these studies illustrate diverse problems related to meiosis and germ cell maturation of the in vitro-derived gametes. The study published by Novak et al, ${ }^{65}$ for example, presented the difficulties related to correct meiotic resolution in mESC-derived oocytes and related aneuploidies. The authors obtained follicular structures from mouse ESCs via EB formation and production of oocyte-like cells with evidence of meiosis. Despite the presence of the meiotic marker SCP3, however, they found no expression of other important meiotic molecules such as SCP1, SCP2, REC8, STAG3, and SMC1-b. Moreover, the chromosomal arrangements in these oocyte-like structures differed from the synaptic disposition of oocytes in vivo. 
To date there is only one report of live offspring obtained from in vitro-derived gametes; efforts to duplicate the studies have not succeeded. ${ }^{58}$ In this work, authors established spermatogonial stem cell lines from mouse ESCs by transfecting them with two reporter genes linked to the late male germ cell marker Stra8 and Prmt1. To induce meiosis, RA was added to the culture media, and EBs were formed. The authors observed the formation of sperm-like cells in vitro that expressed several meiotic and postmeiotic markers after RA addition to the medium. However, the most interesting fact was that they gave rise to haploid sperm with limited motility when transplanted into the testes of previously sterilized recipient mice. Functionality of the in vitro-derived male germ cells was finally demonstrated by their ability to produce live offspring after oocyte fertilization by ICSI. However, all pups showed phenotypic alterations such as growth retardation and died prematurely, perhaps due to abnormal methylation patterns because of a failure to establish germline imprinting in the ESCs-derived gametes.

\section{State of the Art in Germ Cell Differentiation from hESCs and iPSCs}

Advances in germline differentiation from human pluripotent cells are more restricted due to two important bottlenecks: First, obvious limitations make assessment of functional assays difficult with human artificial germ cells obtained from pluripotent cells. Second, human in vitro germline differentiation from hESCs and hiPSCs may be more difficult experimentally with most of the in vitro-derived germ cells arresting in early premeiotic stages of germline formation. Nonetheless, the first evidence of germline formation from hESCs in vitro was reported in 2004 by EB spontaneous differentiation. ${ }^{66}$ This study consisted of a complete characterization of the stage-specific expression of different germ cell markers in both undifferentiated and spontaneously differentiated hESC lines and established a reference model for the germline differentiation in vitro from hESCs. Among their findings, authors showed that undifferentiated hESCs expressed some early germ cell markers such as c-KIT and DAZL, but not late markers such as VASA or SCP3, and they hypothesized that hESCs can be a heterogeneous pluripotent population in which there is a predisposition of some cells to form germ cells spontaneously.

Following this work, several groups reported in vitro formation of human germ cells by using different techniques such as purification of germ cells from spontaneous differentiation experiments, in vitro co-culture models with gonadal tissue, and/or addition of growth factors to the culture media. ${ }^{67-70}$ However, all these reports identified problems with maturation of germ cells derived in vitro and the initiation of meiosis.

Most recently, several reports indicate complete meiotic progression of in vitro-derived germ cells by the ectopic expression of the $D A Z$ gene family members $D A Z 2, D A Z L$, and $B O U L E$ in both hESC and hiPSC lines subjected to spontaneous differentiation. ${ }^{71,72}$ These works showed a new point of view in the field because they were the first reports describing how the genetic modification of the expression of highly conserved RNA-binding proteins can lead to the correct meiotic progression of germ cells in vitro in the absence of a gonadal niche and showed the important regulatory role that posttranscriptional regulation can play in this process. Supporting these results, recent studies reported meiosis induction in in vitro-derived germ cells by the ectopic expression of another highly conserved RNA- 
binding protein in the germline of all metazoan such as VASA. ${ }^{73}$ This evidence provides the first examples of the establishment of genetic and epigenetic models for in vitro germline differentiation from pluripotent stem cells and can help us gain insights about germline regulation. Other studies have reported complete meiosis in in vitro-derived germ cells based on the purification of spontaneous differentiated germ cells and subsequent further culture with a cocktail of growth factors, in the absence of genetic manipulation. ${ }^{74}$ However, the efficiency of formation of haploid cells in all these reports is very low, and further research is needed.

\section{Challenges in Germ Cell Differentiation from Pluripotent Cells}

Even with the advances in recent years in germline differentiation from pluripotent stem cells, we are still far from a complete knowledge of human germ cell development. Among the frontiers, we must explore meiotic completion and posttranscriptional regulation by RNA-binding proteins, and small noncoding RNAs provide exciting challenges and opportunities for inquiry.

\section{Meiosis and Its Molecular Regulation}

Although several reports have demonstrated the in vitro derivation of germ cells from mouse and human pluripotent cell lines, the correct meiotic in vitro progression represents one of the most important challenges. Here, we offer a concise review about our knowledge of meiotic regulation in mammals and the challenges we must overcome to improve the maturation efficiency of in vitro-derived germ cells.

Meiosis in mammals consists of a long prophase I followed by two consecutive cell divisions without DNA replication to generate haploid cells. Cross-linking of homolog chromosomes occurs in prophase I, allowing recombination. As a result of this, chiasmata can be microscopically visualized along with metaphase $\mathrm{I}^{75}$ At the same time, there is a meiotic silencing of unpaired chromatin (MSUC) in sexual chromosomes that results in the formation of a heterochromatic region called the sexual body in meiotic cells. ${ }^{76}$

Prophase I is divided into four consecutive stages: leptotene, zygotene, pachytene, and diplotene. In leptotene, homolog chromosomes are aligned but not yet paired; this process is driven by the formation of a chromosomal scaffold called the synaptonemal complex, formed by cohesins REC8, STAG3, and SMC1B, and axial elements SCP3 and SCP2. In zygotene, topoisomerase SPO11 mediates programmed double-strand breaks of DNA that allow recombination. These breaks are recognized by the recombination repair machinery. Phosphorylation of $\mathrm{H} 2 \mathrm{AX}$ to form $\gamma \mathrm{H} 2 \mathrm{AX}$ is necessary to recruit recombinase-related RECA, DMC1, and RAD51, among others, to repair breaks by homologue recombination. At this stage, pairing of chromosomes is completed, and axial elements become lateral elements of the synaptonemal complex along the strands of the DNA being zipped. Chromosomal synapsis is completed during pachytene driven by the structural function of SCP1 and the central elements SYCE1 and SYCE2. Pachytene is also characterized by the appearance of specific recombination sites (crossovers) while MLH1 and MLH3 mediate mismatch repair of DNA breaks by homologue recombination. Finally, in diplotene, 
chromosomes undergo desynapsis and start to condense. At this stage, recombination sites can be observed by the formation of chiasmata. ${ }^{75}$

Subsequent to prophase I, meiosis is characterized by a first reductional cell division where homologue chromosomes are separated, and a second equational division where sister chromatids are spliced to form haploid daughter cells. As noted earlier, these two consecutive cell divisions without DNA replication occur in a different time point in males and females. In males, these divisions occur subsequently and give raise to four phenotypically similar daughter cells. However, in females, the first division occurs during the follicular recruitment stage, whereas the second one is completed during fertilization. Also in females, divisions are not symmetrical, giving rise to both polar bodies that will degenerate.

Meiosis has several checkpoints at different stages; one of the most important is the spindle assembly checkpoint (SAC). SAC is formed by the mitotic arrest deficient (Mad) proteins MadI and MadII, and budding uninhibited by benzimidazole (Bub) proteins BubI, Bub3, and BubRI, and MpsI. It is a mechanism that detects unattached tubules or loss of tension in the kinetochores of chromosomes during metaphase to ensure the correct segregation of chromosomes. Also, there are several protein complexes such as Ndc80, the chromosomal passenger complex (CPC), the mitotic centromere-associated kinesis (MCAK), the kintochore null I (KNLI) and MisI2 complexes that act as microtubule-kinetochore attachment regulators. ${ }^{77}$

Despite our knowledge of meiotic regulation and checkpoints, mechanisms of meiotic initiation in mammals remain unclear. Unlike yeast, where two well-characterized proteins initiate meiosis, NDT80 and IME2, ${ }^{78}$ in mammals no clear ortholog genes are implicated. To date, we know that RA signaling activation of Stra8 is necessary. ${ }^{34,35}$ However, it has been postulated that germ cell intrinsic factors such as the RNA-binding protein DAZL can act upstream of Stra8 to provide a master regulator of meiotic initiation in mammals in a process called germ cell licensing. ${ }^{79}$ Because of the lack of a conserved regulatory mechanism to enter meiosis between yeast and mammals, posttranscriptional regulation by RNA-binding proteins and micro RNAs (miRNAs) could be key candidates.

\section{Posttranscriptional Regulation by RNA-Binding Proteins and Small Noncoding RNAs}

Posttranscriptional gene regulation is essential in gametogenesis because germ cells are transcriptionally silenced periodically during their development. ${ }^{80}$ The increased levels of miRNA expression in germ cells compared with somatic cells, together with the finding of miRNA clusters on chromosomes 2 and X upregulated in both 14-day mouse neonatal testis and ovaries, is indicative of its relevance in germline development. ${ }^{81}$ Small noncoding RNAs are short single-stranded noncoding RNAs that bind specifically in conjunction with a protein complex to complementary $3^{\prime}$ untranslated regions (UTRs) of target mRNAs and inhibit their translation or induce their degradation. miRNAs are usually transcribed by RNA polymerase II and cleaved by the RNase Drosha to form hairpin loops. ${ }^{82}$ These hairpin loops are recognized by the cytoplasmic endonuclease Dicer and cleaved to form doublestranded mature miRNAs that are loaded into the miRNA-induced silencing complex (miRISC). Finally, the effector miRISC incorporates specific RNA-binding proteins such as 
Argonaute (AGO) that mediate the posttranscriptional regulation of target mRNAs. Thus posttranscriptional regulation efficiency depends on two main components: the complementarity of miRNAs with their target mRNAs and the catalytic activity of their associated RNA-binding proteins.

Implication of miRNAs in germ cell development has been functionally demonstrated by the fact that dicer germline inducible mice knockouts are infertile. ${ }^{83}$ The best characterized miRNA pathway in mammalian germ cells is the repression of the miRNA Let7 by the RNA-binding protein Lin28 to permit Blimp1 translation during the first steps of mouse germ cell determination. ${ }^{84}$ Additionally, the role of the reciprocal regulation pathway of Lin28 and Let7 also extends to later stages of spermatogenesis as pluripotency regulators in conjunction with miR-125a and miR-9. ${ }^{85}$

In recent years, we have seen important advances in the knowledge of the role of miRNAs in germline development. The miRNA cluster miR17-92 is thought to promote survival and proliferation of premeiotic germ cells, and its expression is downregulated in female primordial oocytes following meiotic arrest. ${ }^{83}$ Moreover, miR-125 is implicated in posttranscriptional repression of Oct4 during male meiotic silencing, ${ }^{86}$ whereas miR-181c targets Sox5 and Sox6. Similarly, miR-181c together with miR-181-b and miR-355 target the postmeiotic marker Rsbn I ${ }^{87}$; and miR-320 and miR-214 are predicted to target cell adhesion and heat shock proteins in germ cells, respectively. ${ }^{88}$ Interestingly, it has been shown that the overexpression of the miR-34 family together with the RNA-binding protein Vasa in HeLa cells promoted the expression of germ cell markers, suggesting a possible link between them. ${ }^{89}$ Finally, there are studies predicting that miRNAs such as miR-34b and $34 \mathrm{c}$ can regulate posttranscriptionally the expression of RNA-binding proteins such as DAZL. ${ }^{90}$

In spite of progress, most information regarding miRNA functions in germ cells has two important handicaps. First, because germ cell profiles are different depending on the developmental stage, most profiling done in whole gonadal tissue samples is not totally informative. Second, most miRNA targets in the literature are based on in silico bioinformatic prediction tools that must be experimentally validated. Toward this goal, in vitro-derived germ cells may provide a useful model to confirm predictions experimentally.

Finally, we note there are several highly conserved RNA-binding proteins that have been described as essential for correct germline maturation in mammals. Among them, the $D A Z$ gene family of RNA-binding proteins is one of the most important ones. ${ }^{91-93}$ In humans, this family is composed of the autosome genes BOULE and DAZL together with the cluster of $D A Z$ genes of the $\mathrm{Y}$ chromosome. Because $D A Z L$ and $D A Z$ are expressed only in mammals, there are several pieces of evolutionary evidence that indicate that they come from BOULE, which is also present in invertebrates. ${ }^{92}$ In mice, Dazl is known to be a major regulator of germ cell maintenance gametogenesis. ${ }^{93}$ VASA is another RNA-binding protein that has been postulated as an essential factor in meiosis and germ cell maturation. It is also highly conserved along the germ cells of all metazoans and specifically located in an electron-dense perinuclear structure that is rich in RNAs and other RNA-binding proteins called germplasm. ${ }^{12,94-97}$ In humans and mice, it is encoded by DDX4. This gene is a member of the DEAD-box gene family and transcribe for an ATP-dependent RNA-helicase 
protein that is specifically expressed from the moment of gonadal crest in all perimeiotic stages of mammalian germ cells. ${ }^{94}$ Knockout models for Vasa in Drosophila show defects in polar bodies (aka germplasm) assembly and in oogenesis, ${ }^{97}$ whereas mice knockout animals for $M v h$ (Mouse vasa homolog) show infertility in males. ${ }^{98}$ These facts suggest that although it has been shown essential for germ cell maturation, the role of VASA in germline maturation has changed along with evolution.

Despite the lack of knowledge we have about critical genes in human germ cell development, it has been suggested that genes encoding RNA-binding proteins may encode components that work as chaperones to mediate the correct folding of target RNAs and facilitate their interaction with accessory proteins, as well as posttranscriptional regulators of meiosis-related proteins. Indeed, it has been recently suggested that Dazl is an upstream posttranscriptional regulator of Scp3 and Vasa in mice and that Vasa can target the mRNA encoding another highly conserved proteins such as NANOS3, which maintains mitotic arrest in mice male spermatogonia. ${ }^{23,42,99-102}$

Recent studies suggest that Vasa can target the mRNA that encodes mei-P26 in Drosophila. Interestingly, mei-P26 acts to silencing several target miRNAs families interacting with the Argonaut protein Ago1 and promoting germ cell maturation. In this way, mutant flies for Vasa showed low protein levels of mei-P26, and therefore miRNAs levels became functional in germ cells. ${ }^{103}$ Another report suggested a need for Vasa for correct "ping-pong amplification cycles" of the noncoding family of RNAs, piRNA (Piwi-interacting RNAs). This suggestion was based on the observation that knockout mouse models for Mvh and for the Argonaute-like Piwi homolog proteins Miwi, Mili, and Miwi2 that regulate piRNAs shared the same phenotype. ${ }^{104}$ Because one of the functions of piRNAs is the retrotansposon silencing by de novo methylation of DNA, the phenotype was characterized by meiotic arrest as a consequence of the high expression of retrotansposons. ${ }^{105}$ Moreover, given their functions as retrotransposon silencers, it is possible that piRNAs are also implicated in the meiotic silencing of unpaired chromatin (MSUC) during male meiotic prophase I in mammals. ${ }^{76}$ Further basic studies are needed to understand the existing link of Lin28, Nanos, Dazl, Vasa, Piwi homologs, and other RNA-binding proteins with meiotic progression (Fig. 3).

\section{Concluding Remarks and Future Applications}

The possibility of obtaining functional germ cells from pluripotent stem cell lines is an exciting scientific breakthrough in reproductive medicine. We have reviewed some of the major advances in the field, attempting to highlight challenges that we must be overcome to achieve the correct maturation of germ cells in vitro. In general, we confirm that the generation of germ cells from ESCs and iPSCs has been clearly achieved via several methodologies and that derivation of germ cells in vitro is a viable model to study the insights of mammalian germ cell development, especially their formation. However, derivation efficiencies of mature germ cells are low at best and may differ between species. Nonetheless, gametogenesis is a dynamic process that needs cross-talk between the gonadal niche and the germ cells to orchestrate the correct germline maturation. Thus it is essential to find suitable cell niches that provide the required environment for the proper development 
of gametes in vitro. Creation of defined culture media to enable the complete differentiation process is also desirable, avoiding the use of serum containing unspecified components to improve reproducibility of experiments among groups. Finally, due to the complexity of epigenetic reprogramming of germ cells in vivo, further studies are needed to achieve functionality of in vitro-derived germ cells. Future translational applications of these results to the clinic will still require an enormous amount of work. However, efforts worldwide may provide the framework for success. Toward this goal, we contribute our work to achieve this astonishing breakthrough for the scientific community.

\section{Acknowledgments}

This work was supported by a grant to Jose V. Medrano by Instituto de Salud Carlos III from the Spanish Ministry of Science (FI07/00011) and the National Institutes of Health (NICHD 1U54HD068158-01 to Renee A. Reijo Pera).

\section{References}

1. Ziebe S, Loft A, Petersen JH, et al. Embryo quality and developmental potential is compromised by age. Acta Obstet Gynecol Scand. 2001; 80(2):169-174. [PubMed: 11167214]

2. Adamson GD, de Mouzon J, Lancaster P, Nygren KG, Sullivan E, Zegers-Hochschild F, International Committee for Monitoring Assisted Reproductive Technology. World collaborative report on in vitro fertilization, 2000. Fertil Steril. 2006; 85(6):1586-1622. [PubMed: 16759920]

3. Ginsburg M, Snow MH, McLaren A. Primordial germ cells in the mouse embryo during gastrulation. Development. 1990; 110(2):521-528. [PubMed: 2133553]

4. Hayashi K, de Sousa Lopes SM, Surani MA. Germ cell specification in mice. Science. 2007; 316(5823):394-396. [PubMed: 17446386]

5. Lawson KA, Hage WJ. Clonal analysis of the origin of primordial germ cells in the mouse. Ciba Found Symp. 1994; 182:68-84. discussion 84-91. [PubMed: 7835158]

6. Saitou M, Barton SC, Surani MA. A molecular programme for the specification of germ cell fate in mice. Nature. 2002; 418(6895):293-300. [PubMed: 12124616]

7. Marques-Mari AI, Lacham-Kaplan O, Medrano JV, Pellicer A, Simón C. Differentiation of germ cells and gametes from stem cells. Hum Reprod Update. 2009; 15(3):379-390. [PubMed: 19179344]

8. Evans MJ, Kaufman MH. Establishment in culture of pluripotential cells from mouse embryos. Nature. 1981; 292(5819):154-156. [PubMed: 7242681]

9. Martin GR. Isolation of a pluripotent cell line from early mouse embryos cultured in medium conditioned by teratocarcinoma stem cells. Proc Natl Acad Sci U S A. 1981; 78(12):7634-7638. [PubMed: 6950406]

10. Thomson JA, Itskovitz-Eldor J, Shapiro SS, et al. Embryonic stem cell lines derived from human blastocysts. Science. 1998; 282(5391):1145-1147. [PubMed: 9804556]

11. Takahashi K, Yamanaka S. Induction of pluripotent stem cells from mouse embryonic and adult fibroblast cultures by defined factors. Cell. 2006; 126(4):663-676. [PubMed: 16904174]

12. Fujiwara T, Dunn NR, Hogan BL. Bone morphogenetic protein 4 in the extraembryonic mesoderm is required for allantois development and the localization and survival of primordial germ cells in the mouse. Proc Natl Acad Sci U S A. 2001; 98(24):13739-13744. [PubMed: 11707591]

13. Ying Y, Liu XM, Marble A, Lawson KA, Zhao GQ. Requirement of Bmp8b for the generation of primordial germ cells in the mouse. Mol Endocrinol. 2000; 14(7):1053-1063. [PubMed: 10894154]

14. Ying Y, Qi X, Zhao GQ. Induction of primordial germ cells from murine epiblasts by synergistic action of BMP4 and BMP8B signaling pathways. Proc Natl Acad Sci U S A. 2001; 98(14):78587862. [PubMed: 11427739] 
15. Vincent SD, Dunn NR, Sciammas R, et al. The zinc finger transcriptional repressor Blimp1/Prdm1 is dispensable for early axis formation but is required for specification of primordial germ cells in the mouse. Development. 2005; 132(6):1315-1325. [PubMed: 15750184]

16. Ohinata Y, Payer B, O'Carroll D, et al. Blimp1 is a critical determinant of the germ cell lineage in mice. Nature. 2005; 436(7048):207-213. [PubMed: 15937476]

17. Wylie CC, Stott D, Donovan PJ. Primordial germ cell migration. Dev Biol (N Y 1985). 1986; 2:433-448. [PubMed: 3078122]

18. Goto T, Adjaye J, Rodeck CH, Monk M. Identification of genes expressed in human primordial germ cells at the time of entry of the female germ line into meiosis. Mol Hum Reprod. 1999; 5(9): 851-860. [PubMed: 10460224]

19. Fujimoto T, Miyayama Y, Fuyuta M. The origin, migration and fine morphology of human primordial germ cells. Anat Rec. 1977; 188(3):315-330. [PubMed: 900520]

20. Matsui Y, Zsebo KM, Hogan BL. Embryonic expression of a haematopoietic growth factor encoded by the Sl locus and the ligand for c-kit. Nature. 1990; 347(6294):667-669. [PubMed: 1699134]

21. Donovan PJ, Stott D, Cairns LA, Heasman J, Wylie CC. Migratory and postmigratory mouse primordial germ cells behave differently in culture. Cell. 1986; 44(6):831-838. [PubMed: 3955652]

22. Castrillon DH, Quade BJ, Wang TY, Quigley C, Crum CP. The human VASA gene is specifically expressed in the germ cell lineage. Proc Natl Acad Sci U S A. 2000; 97(17):9585-9590. [PubMed: 10920202]

23. Noce T, Okamoto-Ito S, Tsunekawa N. Vasa homolog genes in mammalian germ cell development. Cell Struct Funct. 2001; 26(3):131-136. [PubMed: 11565805]

24. Tanaka SS, Toyooka Y, Akasu R, et al. The mouse homolog of Drosophila Vasa is required for the development of male germ cells. Genes Dev. 2000; 14(7):841-853. [PubMed: 10766740]

25. Byskov AG. Differentiation of mammalian embryonic gonad. Physiol Rev. 1986; 66(1):71-117. [PubMed: 3511481]

26. Sinclair AH, Berta P, Palmer MS, et al. A gene from the human sex-determining region encodes a protein with homology to a conserved DNA-binding motif. Nature. 1990; 346(6281):240-244. [PubMed: 1695712]

27. McLaren A. Somatic and germ-cell sex in mammals. Philos Trans R Soc Lond B Biol Sci. 1988; 322(1208):3-9. [PubMed: 2907801]

28. Koopman P, Münsterberg A, Capel B, Vivian N, Lovell-Badge R. Expression of a candidate sexdetermining gene during mouse testis differentiation. Nature. 1990; 348(6300):450-452. [PubMed: 2247150]

29. Burgoyne PS. Role of mammalian Y chromosome in sex determination. Philos Trans R Soc Lond B Biol Sci. 1988; 322(1208):63-72. [PubMed: 2907804]

30. Upadhyay S, Zamboni L. Preliminary observations on the role of the mesonephros in the development of the adrenal cortex. Anat Rec. 1982; 202(1):105-111. [PubMed: 7059014]

31. McLaren A. Sex reversal in the mouse. Differentiation. 1983; 23(Suppl):S93-S98. [PubMed: 6444181]

32. McLaren A, Southee D. Entry of mouse embryonic germ cells into meiosis. Dev Biol. 1997; 187(1):107-113. [PubMed: 9224678]

33. McLaren A. Meiosis and differentiation of mouse germ cells. Symp Soc Exp Biol. 1984; 38:7-23. [PubMed: 6400220]

34. Bowles J, Knight D, Smith C, et al. Retinoid signaling determines germ cell fate in mice. Science. 2006; 312(5773):596-600. [PubMed: 16574820]

35. Koubova J, Menke DB, Zhou Q, Capel B, Griswold MD, Page DC. Retinoic acid regulates sexspecific timing of meiotic initiation in mice. Proc Natl Acad Sci U S A. 2006; 103(8):2474-2479. [PubMed: 16461896]

36. Schöler HR, Ruppert S, Suzuki N, Chowdhury K, Gruss P. New type of POU domain in germ linespecific protein Oct-4. Nature. 1990; 344(6265):435-439. [PubMed: 1690859] 
37. Pesce M, Wang X, Wolgemuth DJ, Schöler H. Differential expression of the Oct-4 transcription factor during mouse germ cell differentiation. Mech Dev. 1998; 71(1-2):89-98. [PubMed: 9507072]

38. Heyting C, Dettmers RJ, Dietrich AJ, Redeker EJ, Vink AC. Two major components of synaptonemal complexes are specific for meiotic prophase nuclei. Chromosoma. 1988; 96(4):325332. [PubMed: 3289856]

39. Dobson MJ, Pearlman RE, Karaiskakis A, Spyropoulos B, Moens PB. Synaptonemal complex proteins: occurrence, epitope mapping and chromosome disjunction. J Cell Sci. 1994; 107(Pt 10): 2749-2760. [PubMed: 7876343]

40. Yoshida K, Kondoh G, Matsuda Y, Habu T, Nishimune Y, Morita T. The mouse RecA-like gene Dmc1 is required for homologous chromosome synapsis during meiosis. Mol Cell. 1998; 1(5): 707-718. [PubMed: 9660954]

41. Pittman DL, Cobb J, Schimenti KJ, et al. Meiotic prophase arrest with failure of chromosome synapsis in mice deficient for Dmc1, a germline-specific RecA homolog. Mol Cell. 1998; 1(5): 697-705. [PubMed: 9660953]

42. Reynolds N, Collier B, Bingham V, Gray NK, Cooke HJ. Translation of the synaptonemal complex component Sycp3 is enhanced in vivo by the germ cell specific regulator Dazl. RNA. 2007; 13(7):974-981. [PubMed: 17526644]

43. Bellvé AR, Millette CF, Bhatnagar YM, O'Brien DA. Dissociation of the mouse testis and characterization of isolated spermatogenic cells. J Histochem Cytochem. 1977; 25(7):480-494. [PubMed: 893996]

44. McLaren A. Germ cells and germ cell sex. Philos Trans R Soc Lond B Biol Sci. 1995; 350(1333): 229-233. [PubMed: 8570686]

45. Bestor TH. The DNA methyltransferases of mammals. Hum Mol Genet. 2000; 9(16):2395-2402. [PubMed: 11005794]

46. Bestor T, Laudano A, Mattaliano R, Ingram V. Cloning and sequencing of a cDNA encoding DNA methyltransferase of mouse cells. The carboxyl-terminal domain of the mammalian enzymes is related to bacterial restriction methyltransferases. J Mol Biol. 1988; 203(4):971-983.

47. Okano M, Xie S, Li E. Cloning and characterization of a family of novel mammalian DNA (cytosine-5) methyltransferases. Nat Genet. 1998; 19(3):219-220. [PubMed: 9662389]

48. Lyle R. Gametic imprinting in development and disease. J Endocrinol. 1997; 155(1):1-12. [PubMed: 9390000]

49. Miozzo M, Simoni G. The role of imprinted genes in fetal growth. Biol Neonate. 2002; 81(4):217228. [PubMed: 12011565]

50. Surani MA. Reprogramming of genome function through epigenetic inheritance. Nature. 2001; 414(6859):122-128. [PubMed: 11689958]

51. Reik W, Dean W, Walter J. Epigenetic reprogramming in mammalian development. Science. 2001; 293(5532):1089-1093. [PubMed: 11498579]

52. Rideout WM III, Eggan K, Jaenisch R. Nuclear cloning and epigenetic reprogramming of the genome. Science. 2001; 293(5532):1093-1098. [PubMed: 11498580]

53. Maatouk DM, Resnick JL. Continuing primordial germ cell differentiation in the mouse embryo is a cell-intrinsic program sensitive to DNA methylation. Dev Biol. 2003; 258(1):201-208. [PubMed: 12781693]

54. Davis TL, Yang GJ, McCarrey JR, Bartolomei MS. The H19 methylation imprint is erased and reestablished differentially on the parental alleles during male germ cell development. Hum Mol Genet. 2000; 9(19):2885-2894. [PubMed: 11092765]

55. Ueda T, Abe K, Miura A, et al. The paternal methylation imprint of the mouse H19 locus is acquired in the gonocyte stage during foetal testis development. Genes Cells. 2000; 5(8):649-659. [PubMed: 10947850]

56. Everman DB, Cassidy SB. Genetics of childhood disorders: XII. Genomic imprinting: breaking the rules. J Am Acad Child Adolesc Psychiatry. 2000; 39(3):386-389.

57. Tycko B, Morison IM. Physiological functions of imprinted genes. J Cell Physiol. 2002; 192(3): 245-258. [PubMed: 12124770] 
58. Nayernia K, Nolte J, Michelmann HW, et al. In vitro-differentiated embryonic stem cells give rise to male gametes that can generate offspring mice. Dev Cell. 2006; 11(1):125-132. [PubMed: 16824959]

59. Hübner K, Fuhrmann G, Christenson LK, et al. Derivation of oocytes from mouse embryonic stem cells. Science. 2003; 300(5623):1251-1256. [PubMed: 12730498]

60. Toyooka Y, Tsunekawa N, Akasu R, Noce T. Embryonic stem cells can form germ cells in vitro. Proc Natl Acad Sci U S A. 2003; 100(20):11457-11462. [PubMed: 14504407]

61. Geijsen N, Horoschak M, Kim K, Gribnau J, Eggan K, Daley GQ. Derivation of embryonic germ cells and male gametes from embryonic stem cells. Nature. 2004; 427(6970):148-154. [PubMed: 14668819]

62. Kerkis A, Fonseca SA, Serafim RC, et al. In vitro differentiation of male mouse embryonic stem cells into both presumptive sperm cells and oocytes. Cloning Stem Cells. 2007; 9(4):535-548. [PubMed: 18154514]

63. Lacham-Kaplan O, Chy H, Trounson A. Testicular cell conditioned medium supports differentiation of embryonic stem cells into ovarian structures containing oocytes. Stem Cells. 2006; 24(2):266-273. [PubMed: 16109761]

64. Qing T, Shi Y, Qin H, et al. Induction of oocyte-like cells from mouse embryonic stem cells by coculture with ovarian granulosa cells. Differentiation. 2007; 75(10):902-911. [PubMed: 17490416]

65. Novak I, Lightfoot DA, Wang H, Eriksson A, Mahdy E, Höög C. Mouse embryonic stem cells form follicle-like ovarian structures but do not progress through meiosis. Stem Cells. 2006; 24(8): 1931-1936. [PubMed: 16644921]

66. Clark AT, Bodnar MS, Fox MS, et al. Spontaneous differentiation of germ cells from human embryonic stem cells in vitro. Hum Mol Genet. 2004; 13(7):727-739. [PubMed: 14962983]

67. Tilgner K, Atkinson SP, Golebiewska A, Stojkovic M, Lako M, Armstrong L. Isolation of primordial germ cells from differentiating human embryonic stem cells. Stem Cells. 2008; 26(12): 3075-3085. [PubMed: 18802037]

68. Park TS, Galic Z, Conway AE, et al. Derivation of primordial germ cells from human embryonic and induced pluripotent stem cells is significantly improved by coculture with human fetal gonadal cells. Stem Cells. 2009; 27(4):783-795. [PubMed: 19350678]

69. Bucay N, Yebra M, Cirulli V, et al. A novel approach for the derivation of putative primordial germ cells and Sertoli cells from human embryonic stem cells. Stem Cells. 2009; 27(1):68-77. [PubMed: 18845765]

70. Kee K, Gonsalves JM, Clark AT, Pera RA. Bone morphogenetic proteins induce germ cell differentiation from human embryonic stem cells. Stem Cells Dev. 2006; 15(6):831-837. [PubMed: 17253946]

71. Kee K, Angeles VT, Flores M, Nguyen HN, Reijo Pera RA. Human DAZL, DAZ and BOULE genes modulate primordial germ-cell and haploid gamete formation. Nature. 2009; 462(7270): 222-225. [PubMed: 19865085]

72. Panula S, Medrano JV, Kee K, et al. Human germ cell differentiation from fetal- and adult-derived induced pluripotent stem cells. Hum Mol Genet. 2011; 20(4):752-762. [PubMed: 21131292]

73. Medrano JV, Ramathal C, Nguyen HN, Simon C, Reijo Pera RA. Divergent RNA-binding proteins, DAZL and VASA, induce meiotic progression in human germ cells derived in vitro. Stem Cells. 2012; 30(3):441-451. [PubMed: 22162380]

74. Eguizabal C, Montserrat N, Vassena R, et al. Complete meiosis from human induced pluripotent stem cells. Stem Cells. 2011; 29(8):1186-1195. [PubMed: 21681858]

75. Handel MA, Schimenti JC. Genetics of mammalian meiosis: regulation, dynamics and impact on fertility. Nat Rev Genet. 2010; 11(2):124-136. [PubMed: 20051984]

76. Burgoyne PS, Mahadevaiah SK, Turner JM. The consequences of asynapsis for mammalian meiosis. Nat Rev Genet. 2009; 10(3):207-216. [PubMed: 19188923]

77. Sun SC, Kim NH. Spindle assembly checkpoint and its regulators in meiosis. Hum Reprod Update. 2012; 18(1):60-72. [PubMed: 22086113]

78. Kassir Y, Adir N, Boger-Nadjar E, et al. Transcriptional regulation of meiosis in budding yeast. Int Rev Cytol. 2003; 224:111-171. [PubMed: 12722950] 
79. Gill ME, Hu YC, Lin Y, Page DC. Licensing of gametogenesis, dependent on RNA binding protein DAZL, as a gateway to sexual differentiation of fetal germ cells. Proc Natl Acad Sci U S A. 2011; 108(18):7443-7448. [PubMed: 21504946]

80. Papaioannou MD, Nef S. microRNAs in the testis: building up male fertility. J Androl. 2010; 31(1):26-33. [PubMed: 19875496]

81. Buchold GM, Coarfa C, Kim J, Milosavljevic A, Gunaratne PH, Matzuk MM. Analysis of microRNA expression in the prepubertal testis. PLoS ONE. 2010; 5(12):e15317. [PubMed: 21206922]

82. Han J, Pedersen JS, Kwon SC, et al. Posttranscriptional cross-regulation between Drosha and DGCR8. Cell. 2009; 136(1):75-84. [PubMed: 19135890]

83. Hayashi K, Chuva de Sousa Lopes SM, Kaneda M, et al. MicroRNA biogenesis is required for mouse primordial germ cell development and spermatogenesis. PLoS ONE. 2008; 3(3):e1738. [PubMed: 18320056]

84. West JA, Viswanathan SR, Yabuuchi A, et al. A role for Lin28 in primordial germ-cell development and germ-cell malignancy. Nature. 2009; 460(7257):909-913. [PubMed: 19578360]

85. Zhong X, Li N, Liang S, Huang Q, Coukos G, Zhang L. Identification of microRNAs regulating reprogramming factor LIN28 in embryonic stem cells and cancer cells. J Biol Chem. 2010; 285(53):41961-41971. [PubMed: 20947512]

86. Western PS, van den Bergen JA, Miles DC, Sinclair AH. Male fetal germ cell differentiation involves complex repression of the regulatory network controlling pluripotency. FASEB J. 2010; 24(8):3026-3035. [PubMed: 20395456]

87. Yan N, Lu Y, Sun H, et al. A microarray for microRNA profiling in mouse testis tissues. Reproduction. 2007; 134(1):73-79. [PubMed: 17641090]

88. Marcon E, Babak T, Chua G, Hughes T, Moens PB. miRNA and piRNA localization in the male mammalian meiotic nucleus. Chromosome Res. 2008; 16(2):243-260. [PubMed: 18204908]

89. Bouhallier F, Allioli N, Lavial F, et al. Role of miR-34c microRNA in the late steps of spermatogenesis. RNA. 2010; 16(4):720-731. [PubMed: 20150330]

90. Luo L, Ye L, Liu G, et al. Microarray-based approach identifies differentially expressed microRNAs in porcine sexually immature and mature testes. PLoS ONE. 2010; 5(8):e11744. [PubMed: 20805883]

91. Juliano C, Wessel G. Developmental biology. Versatile germline genes. Science. 2010; 329(5992): 640-641. [PubMed: 20689009]

92. Xu EY, Moore FL, Pera RA. A gene family required for human germ cell development evolved from an ancient meiotic gene conserved in metazoans. Proc Natl Acad Sci U S A. 2001; 98(13): 7414-7419. [PubMed: 11390979]

93. Ruggiu M, Speed R, Taggart M, et al. The mouse Dazla gene encodes a cytoplasmic protein essential for gametogenesis. Nature. 1997; 389(6646):73-77. [PubMed: 9288969]

94. Castrillon DH, Quade BJ, Wang TY, Quigley C, Crum CP. The human VASA gene is specifically expressed in the germ cell lineage. Proc Natl Acad Sci U S A. 2000; 97(17):9585-9590. [PubMed: 10920202]

95. Gruidl ME, Smith PA, Kuznicki KA, et al. Multiple potential germ-line helicases are components of the germ-line-specific P granules of Caenorhabditis elegans. Proc Natl Acad Sci U S A. 1996; 93(24):13837-13842. [PubMed: 8943022]

96. Komiya T, Itoh K, Ikenishi K, Furusawa M. Isolation and characterization of a novel gene of the DEAD box protein family which is specifically expressed in germ cells of Xenopus laevis. Dev Biol. 1994; 162(2):354-363. [PubMed: 8150200]

97. Lasko PF, Ashburner M. The product of the Drosophila gene Vasa is very similar to eukaryotic initiation factor-4A. Nature. 1988; 335(6191):611-617. [PubMed: 3140040]

98. Tanaka SS, Toyooka Y, Akasu R, et al. The mouse homolog of Drosophila Vasa is required for the development of male germ cells. Genes Dev. 2000; 14(7):841-853. [PubMed: 10766740]

99. Mohr S, Stryker JM, Lambowitz AM. A DEAD-box protein functions as an ATP-dependent RNA chaperone in group I intron splicing. Cell. 2002; 109(6):769-779. [PubMed: 12086675] 
100. Reynolds N, Collier B, Maratou K, et al. Dazl binds in vivo to specific transcripts and can regulate the pre-meiotic translation of Mvh in germ cells. Hum Mol Genet. 2005; 14(24):3899_ 3909. [PubMed: 16278232]

101. Becalska AN, Gavis ER. Lighting up mRNA localization in Drosophila oogenesis. Development. 2009; 136(15):2493-2503. [PubMed: 19592573]

102. Saga Y. Sexual development of mouse germ cells: Nanos2 promotes the male germ cell fate by suppressing the female pathway. Dev Growth Differ. 2008; 50(Suppl 1):S141-S147. [PubMed: 18430166]

103. Liu N, Han H, Lasko P. Vasa promotes Drosophila germline stem cell differentiation by activating mei-P26 translation by directly interacting with a (U)-rich motif in its $3^{\prime}$ UTR. Genes Dev. 2009; 23(23):2742-2752. [PubMed: 19952109]

104. Peters L, Meister G. Argonaute proteins: mediators of RNA silencing. Mol Cell. 2007; 26(5): 611-623. [PubMed: 17560368]

105. Kuramochi-Miyagawa S, Watanabe T, Gotoh K, et al. MVH in piRNA processing and gene silencing of retrotransposons. Genes Dev. 2010; 24(9):887-892. [PubMed: 20439430] 


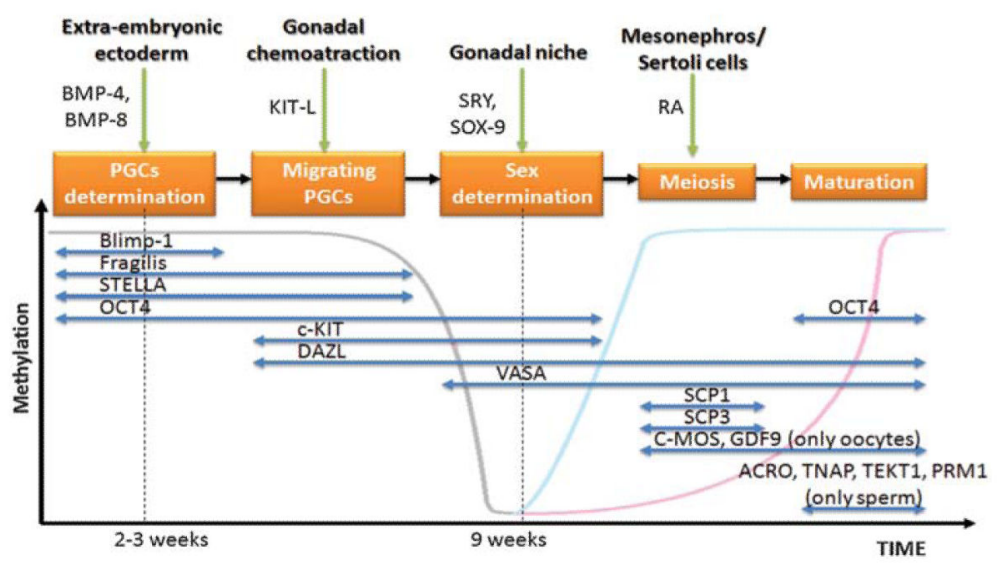

Figure 1.

Schematic representation of the overlap between the stages and the epigenetic reprogramming cycle of human germline differentiation in vivo. Stages of germline differentiation are indicated within boxes. Tissue and/or cellular inducers with their signaling molecules are indicated above each differentiation stage; the specific molecular markers are indicated below. Gray line indicates methylation status of primordial germ cells (PGCs) before sex determination. Pink line indicates methylation status of female genome, and blue line indicates methylation status of male genome. 


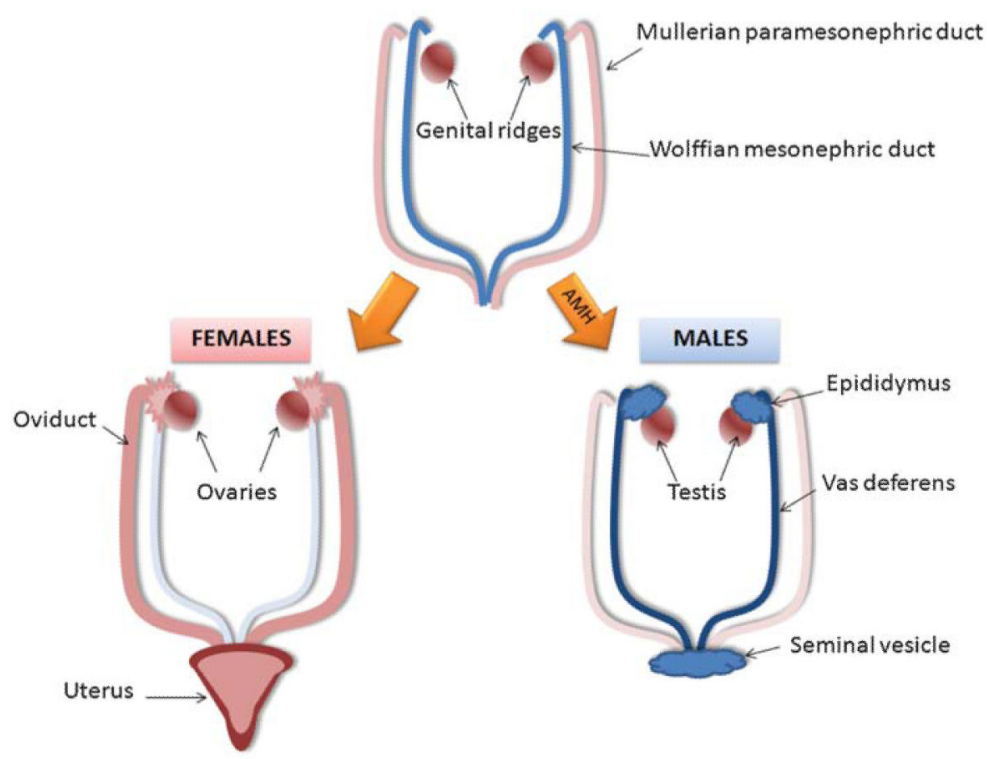

Figure 2.

Sexual differentiation of the genital duct system. At the bipotential genital ducts, both Müllerian and Wolffian ducts are present. However, the Müllerian ducts degenerate in response to anti-Müllerian hormone (AMH) secreted by the testicular Sertoli cells, and the Wolffian ducts differentiate into epididymides, vasa deferentia, and seminal vesicles under the control of androgens produced by Leydig cells. In females, the Müllerian duct differentiates into oviduct, uterus, and upper vagina, and the Wolffian duct degenerates. 


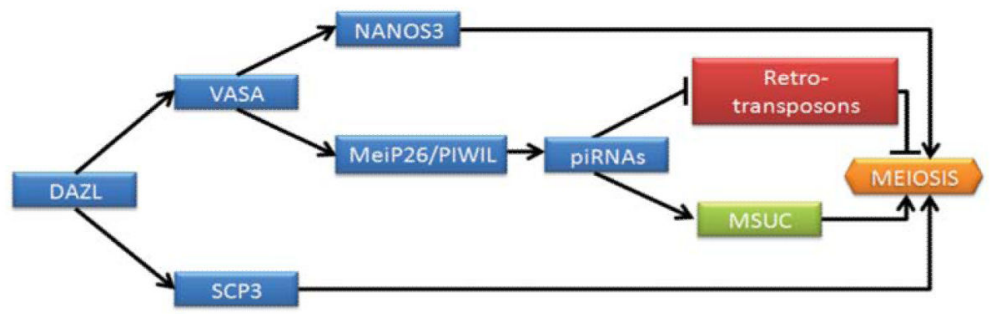

Figure 3.

Proposed model for the regulation of meiotic progression by RNA-binding proteins. In this model, DAZL is a translational regulator of VASA and SCP3. Thus, VASA is implicated in NANOS3 regulation as well in mei-P26 and PIWI proteins that control piRNA expression. These piRNAs silence retro-transposons, which is necessary for the correct MSUC and meiotic progression. 